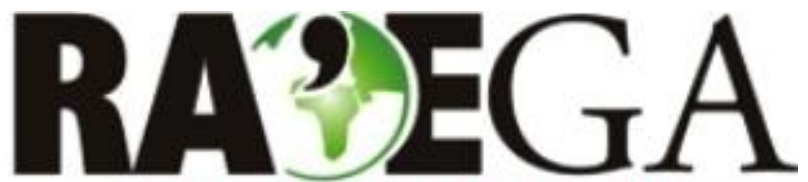

O ESPAÇO GEOGRÁFICO EM ANÁLISE

\title{
VARIAÇÕES ESPACIAIS DAS TEMPERATURAS NOTURNAS EM PRESIDENTE PRUDENTE-SP EM EPISÓDIOS DE VERÃO ${ }^{1}$
}

\author{
SPATIAL VARIATIONS OF AIR TEMPERATURES IN PRESIDENTE PRUDENTE, SÃO PAULO, DURING \\ SUMMER NIGHTS
}

\section{RESUMO}

\author{
Renata dos Santos Cardoso², Margarete Cristiane de Costa Trindade Amorim ${ }^{3}$
}

As características de uso e cobertura da terra nas áreas urbanas são diversas, e o ambiente térmico urbano varia não apenas em relação às áreas rurais circundantes, mas também dentro da área urbana. Portanto, entender as causas dessa variabilidade intraurbana da temperatura é um primeiro passo para contribuir com o planejamento urbano. O objetivo desse artigo foi analisar as variações espaciais da temperatura do ar em Presidente Prudente-SP, registradas através de transectos móveis noturnos durante episódios de verão. Os gráficos com os perfis térmicos, a ilustração das características do sítio urbano e do rural ao longo dos trajetos e os perfis topográficos permitiram a visualização das variações de temperatura do ar com os diferentes tipos de uso e cobertura da terra e padrões construtivos. Os resultados indicaram a formação de ilhas de calor de magnitude moderada a forte, com intensidades entre $3,5^{\circ} \mathrm{C}$ e $5,5^{\circ} \mathrm{C}$, sendo que as características mais importantes na diferenciação entre as áreas mais aquecidas e as áreas com temperaturas reduzidas foram a presença de cobertura vegetal, a morfologia da superfície, as condições meteorológicas de cada dia de registro e as atividades antropogênicas.

PALAVRAS-CHAVE: Clima urbano; ilhas de calor; transectos móveis

\section{ABSTRACT}

Land use and land cover characteristics of urban areas are diverse, and the urban thermal environment varies not only in its rural surroundings but also within the urban area. Therefore, understanding the causes of this intraurban variability in urban climate is the first step for improving urban planning. We analyze spatial variations of air temperature in Presidente Prudente, São Paulo, using automobile traverses during summer nights. The evaluation of temperature profiles, illustrations of urban and rural sites, and topographic profiles allow us to visualize the air temperature variations among different land use and land cover types and urban built forms. Results show the formation of urban heat islands, and their intensity ranges between $3.5^{\circ} \mathrm{C}$ and $5.5^{\circ} \mathrm{C}$. The most important characteristics separating the warmest from the coolest sites were the presence of vegetation, surface morphology, meteorological conditions of each day of measurement, and anthropogenic activities

KEY-WORDS: Urban climate; heat islands; mobile traverses.

Recebido em: 20/07/2016

Aceito em: 18/07/2017

\footnotetext{
${ }^{1}$ Apoio financeiro da Fundação de Amparo à Pesquisa do Estado de São Paulo (FAPESP), processo n. 2013/02057-0.

2 Universidade Estadual Paulista "Júlio de Mesquita Filho", UNESP, Presidente Prudente/SP, e-mail: renatacardoso16@gmail.com

${ }^{3}$ Universidade Estadual Paulista "Júlio de Mesquita Filho", UNESP, Presidente Prudente/SP, e-mail: mccta@fct.unesp.br
} 


\section{VARIAÇÕES ESPACIAIS DAS TEMPERATURAS NOTURNAS EM PRESIDENTE PRUDENTE-SP EM EPISÓDIOS DE VERÃO}

\section{INTRODUÇÃO}

O processo de urbanização promove diversas alterações nas áreas urbanas, decorrentes do intenso adensamento e verticalização que criam rugosidades na superfície e modificam as trocas de energia entre a superfície e a baixa troposfera. Logo, os diversos arranjos paisagísticos formados a partir das transformações no ambiente urbano interferem nas características do clima sobre as cidades, e todo esse jogo de inter-relações requer uma estrutura teórica e metodológica para a compreensão do fato urbano.

Nesse sentido, destaca-se a proposta de investigação destas interferências nos climas das cidades elaborada por Monteiro (1976), o Sistema Clima Urbano (S.C.U), que apresentou uma forma de análise integrada entre os condicionantes urbanos e os geoambientais de cada ambiente específico, com a finalidade de compreender as variações dos atributos climáticos.

Ao considerar o clima das cidades como "um sistema que abrange o clima de um dado espaço terrestre e sua urbanização", Monteiro (1976, p. 95) sugere que o clima urbano é específico para cada ambiente urbanizado, uma vez que as cidades se diferem de acordo com seus condicionantes geoecológicos e urbanos. Dessa forma, entende-se que a proposta formulada pelo autor envolve não só os elementos de ordem meteorológica da atmosfera, mas a articulação desses com os elementos da paisagem urbana em sua dinâmica.

Por isso, para analisar o clima local é necessário adentrar a cidade e identificar os aspectos dos diferentes dinamismos da vida urbana, tais como: as características do sítio urbano, o tráfego de veículos automotores, a remoção da cobertura vegetal, e o adensamento de construções. Sendo que o estudo do clima da cidade também precisa levar em consideração o seu entorno, articulando o urbano com o suburbano e o rural.

Com relação ao ambiente urbano, devido às diferenças na cobertura da terra, características da superfície e o nível de atividade humana, o balanço de energia se difere das áreas rurais circundantes. Tais diferenças podem afetar a geração e a transferência de calor, o que pode levar a diferentes temperaturas de superfície e do ar entre esses ambientes, e a formação do fenômeno ilha de calor nas cidades (VAN HOVE et al., 2011). A existência da ilha de calor urbana (ICU) tem sido documentada há mais de um século (MYRUP, 1969) e, em geral, a ICU atmosférica pode ser dividida em dois tipos: ilha de calor na camada do dossel, que se estende do solo até o nível médio das coberturas dos edifícios, e ilha de calor na camada de limite urbana, situada diretamente acima do dossel urbano e que se refere à parte da camada limite planetária (OKE, 1976).

A intensidade da ICU em uma determinada cidade é o resultado da interação de vários fatores, em diferentes escalas espaciais e temporais. Desde a latitude ou zona climática, o relevo, a maritimidade e continentalidade, até o tamanho da cidade, a forma urbana, e a população (produção de calor antropogênico), têm influência sobre a intensidade da ICU.

Segundo Van Hove et al. (2011), também pode ser feita uma distinção entre os fatores controláveis e incontroláveis (naturais) na variação da intensidade da ICU, e uma categorização entre os efeitos do tempo atmosférico, como a velocidade do vento e cobertura de nuvens, os efeitos permanentes, tais como as áreas verdes, materiais de construção e geometria (fator de visão do céu), e os efeitos cíclicos, tais como a radiação solar e as fontes antropogênicas de calor.

Como as áreas urbanas não são homogêneas em suas características de uso e cobertura da superfície e o campo térmico não só varia em relação às áreas rurais circundantes, mas também dentro da própria área urbana, compreender as causas dessa variabilidade intraurbana da ilha de calor é um primeiro passo para contribuir com o planejamento urbano. Portanto, o objetivo desse artigo consiste em avaliar as variações espaciais da temperatura do ar em Presidente Prudente-SP, registradas 


\section{VARIAÇÕES ESPACIAIS DAS TEMPERATURAS NOTURNAS EM PRESIDENTE PRUDENTE-SP EM EPISÓDIOS DE VERÃO}

através de transectos móveis noturnos durante episódios de verão.

A cidade está localizada no oeste do Estado de São Paulo, com área urbana de aproximadamente $60 \mathrm{~km}^{2}$ e população estimada de 223.749 habitantes (IBGE, 2016). Considerando-se que a ilha de calor sintetiza um conjunto de mudanças decorrentes do tipo de uso e cobertura da terra (AMORIM e MONTEIRO, 2011), Presidente Prudente apresenta diversos problemas que podem interferir no conforto térmico, tais como: diminuição das superfícies naturais cobertas por vegetação, impermeabilização do solo, terrenos pequenos densamente construídos, entre outros.

Embora o clima urbano em Presidente Prudente seja investigado há mais de uma década (AMORIM, 2000, 2005; AMORIM, DUBREUIL, QUENOL E SANT'ANNA NETO, 2009; BARBOSA E AMORIM, 2012; AMORIM, DUBREUIL e CARDOSO, 2015), a expansão da cidade e a implantação de grandes aglomerados habitacionais, associados a um padrão construtivo aquém do adequado às características climáticas tropicais que a cidade se encontra (CARDOSO e AMORIM, 2015), requer uma contínua investigação das ilhas de calor, visto que o fenômeno pode exacerbar o estresse térmico e comprometer a qualidade de vida da população.

\section{MATERIAIS E MÉTODOS}

Para Monteiro (1990, p. 60), o procedimento preliminar básico para investigar o clima de uma cidade consiste em dirigir-se "à análise do campo térmico, a partir do qual, todo um jogo de correlações e interações se produz na geração das características climáticas da cidade".

Durante esse processo, o autor sugere que no caso de as condições não serem favoráveis à “abordagem 'em área' é preferível concentrar-se a observação ao longo de um eixo ou transecto (setor transversal). Também ele, deve expressar as partes - pelo menos as fundamentais e mais expressivas - do todo complexo que é a cidade" (MONTEIRO, 1990, p. 63).
Portanto, para o mapeamento da temperatura ar em Presidente Prudente foram realizados levantamentos móveis pela cidade, metodologia que consiste na definição das áreas de interesse e medições através de sensores acoplados em automóveis. Normalmente, o melhor período para executar esse procedimento é após poucas horas depois do pôr-do-sol em noites com fluxo de ar relativamente calmo e céu sem nuvens, situação na qual as diferenças climáticas locais são maximizadas, revelando áreas de anomalia térmica (OKE, 1977, 2006; PRESTON-WHYTE, 1970; ELIASSON, 1996; AMORIM, 2005; STEWART, 2011; JAMEI E OSSEN, 2012; UGEDA JÚNIOR, 2012; ORTIZ PORANGABA, 2015).

A principal vantagem das medidas itinerantes através dos transectos é que se obtêm registros de temperatura do ar em um grande número de pontos, com dados de diferentes tipos de uso e cobertura da terra, relevo e vegetação. Por outro lado, é válido ressaltar que este procedimento envolve alguns desafios, como a mensuração não simultânea dos dados, a necessidade de manter as medidas nos mesmos pontos em dias diferentes, a dificuldade para definir percursos representativos, bem como o fato do monitoramento se restringir apenas às vias de circulação de automóveis (FIALHO, 2009; AMORIM, 2017).

Outro fator relevante para a realização das medidas móveis consiste na observação dos tipos de tempo. Nesse estudo, a escolha dos dias de medição foi definida com o acompanhamento das imagens do satélite GOES e da previsão do tempo no site do Climatempo e do CPTEC (Centro de Previsão de Tempo e Estudos Climáticos), para visualizar o sistema atuante e analisar as condições atmosféricas favoráveis à execução dos transectos móveis.

A Fig. 1 ilustra os trajetos definidos para a cidade, que visaram contemplar grande parte das formas de ocupação no intraurbano, com o início e término nas proximidades do rural. As medições ocorreram no período noturno, às $21 \mathrm{~h}$, em episódios representativos do verão (dias 12, 13, 15 e 16 de dezembro de 2013). Os 


\section{VARIAÇÕES ESPACIAIS DAS TEMPERATURAS NOTURNAS EM PRESIDENTE PRUDENTE-SP EM EPISÓDIOS DE VERÃO}

equipamentos utilizados foram dois termohigrômetros digitais, modelo 7664.01.0.00 (precisão de $\pm 0,1^{\circ} \mathrm{C}$ ), acoplados em hastes de bambu com cerca de $1,80 \mathrm{~m}$, posicionadas nas laterais dos veículos.

Apesar de se utilizar sensores do mesmo modelo, os equipamentos foram previamente testados em um mesmo ambiente e não apresentaram diferenças significativas diante dos resultados obtidos com as medições $\left(0,1^{\circ} \mathrm{C}\right)$. Além disso, antes de iniciar cada rota, foi dado tempo suficiente para permitir que os sensores respondessem à exposição externa. Em seguida, dois veículos percorreram simultaneamente os percursos a uma velocidade máxima de $30 \mathrm{~km} / \mathrm{h}$, sem ultrapassar $1 \mathrm{~h}$ de duração, com o total de 275 pontos medidos (155 registros no percurso oeste-leste e 120 registros no sul-norte).

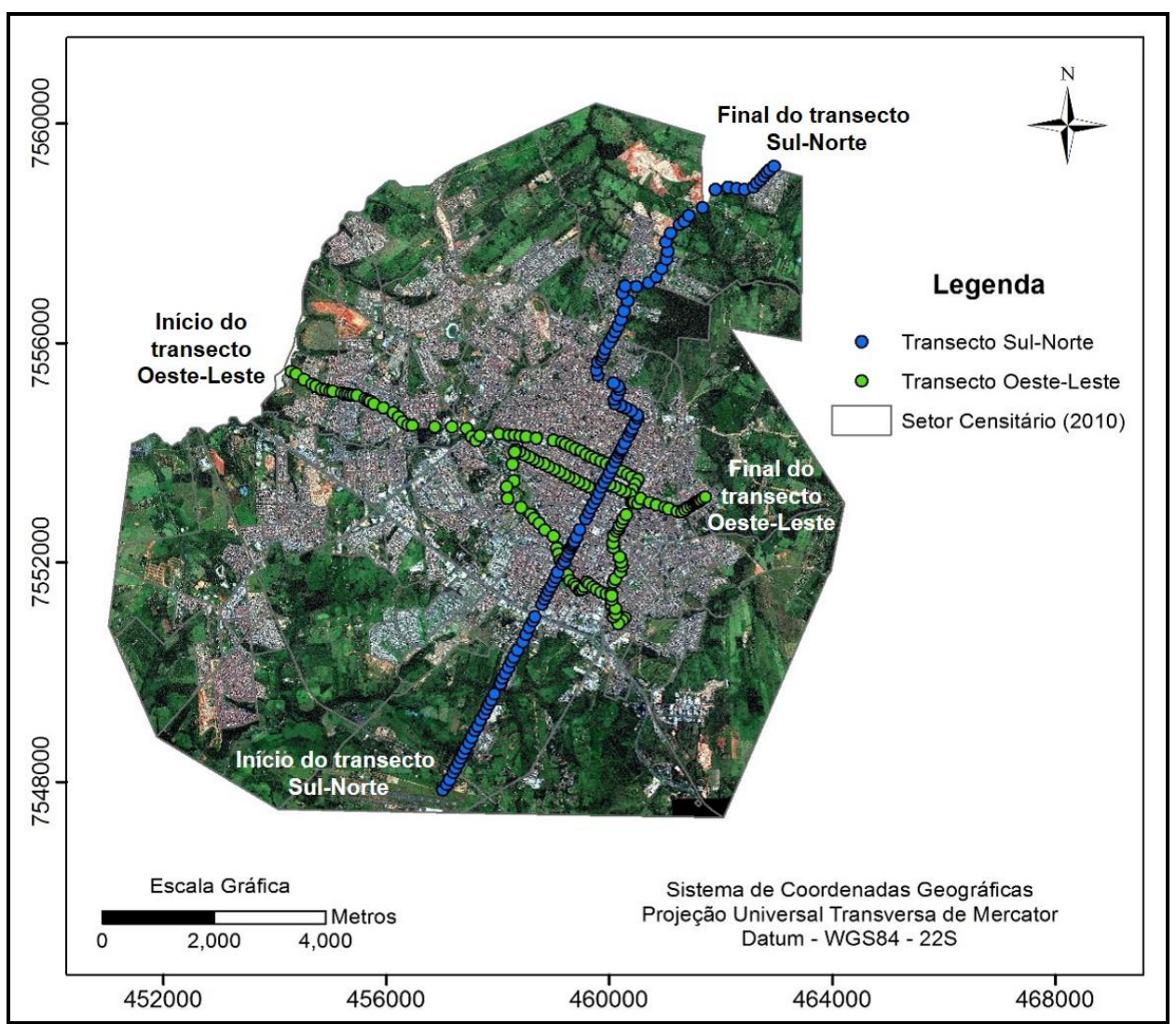

Figura 1 - Trajetos dos transectos móveis em Presidente Prudente. Fonte: Elaborado pela autora

Com o objetivo de padronizar as medições e compensar o tempo de resposta dos sensores às variações de temperatura do ar, os dados foram registrados manualmente ao final de cada quarteirão (distância média de aproximadamente $100 \mathrm{~m}$ entre os pontos).

Posteriormente, os dados foram tabulados para a elaboração dos gráficos com os perfis térmicos, as ilustrações das características do sítio ao longo dos trajetos e os perfis topográficos de cada um, o que facilitou a visualização das variações de temperatura do ar com os diferentes tipos de uso e cobertura da terra e padrões construtivos. Com a localização de cada ponto de medição também foi possível espacializar os dados de temperatura na malha georreferenciada da cidade através do software ArcGIS ${ }^{4}$.

\section{RESULTADOS E DISCUSSÃO}

\footnotetext{
${ }^{4}$ ArcGIS é marca registrada da ESRI - GIS Mapping Software, Solutions, Services, Map Apps, and Data.
} 


\section{VARIAÇÕES ESPACIAIS DAS TEMPERATURAS NOTURNAS EM PRESIDENTE PRUDENTE-SP EM EPISÓDIOS DE VERÃO}

\subsection{ANÁLISE DOS TRANSECTOS MÓVEIS NOTURNOS}

Os dados levantados durante os quatro dias de transectos indicam a formação de ilhas de calor de magnitude moderada a forte, segundo a classificação de García (1995), com diferenças entre $3,5^{\circ} \mathrm{C}$ e $5,5^{\circ} \mathrm{C}$.

No início das medições móveis no dia 12 de dezembro, quinta-feira, a velocidade do vento registrada pela Estação Meteorológica da FCT/UNESP foi de $2,5 \mathrm{~m} / \mathrm{s}$, com direção predominante de sudeste e pressão atmosférica de $958,7 \mathrm{hPa}$. Nesse dia, sob a atuação da massa Equatorial Continental ( $\mathrm{mEc}$ ), a diferença térmica foi de $3,8^{\circ} \mathrm{C}$ e a temperatura mais elevada foi registrada no início do percurso oeste-leste $\left(28,2^{\circ} \mathrm{C}\right)$ (Fig. 2), onde há o predomínio de residências populares e a maior ocorrência de telhados de fibrocimento.

Com relação às temperaturas registradas no transecto oeste-leste em direção ao centro da cidade, cujas características do trecho urbanizado correspondem a uma mistura de área de comércio, serviço e residencial de alta densidade populacional com ocupação horizontal e vertical, não houve grandes variações $\left(26,8^{\circ} \mathrm{C}\right.$ a $\left.27,1^{\circ} \mathrm{C}\right)$. Apesar das diferenciações no relevo nesse trajeto, os fundos de vale são densamente construídos e com pouca cobertura arbórea, diminuindo a capacidade dessa característica do relevo em diminuir as temperaturas do entorno. 


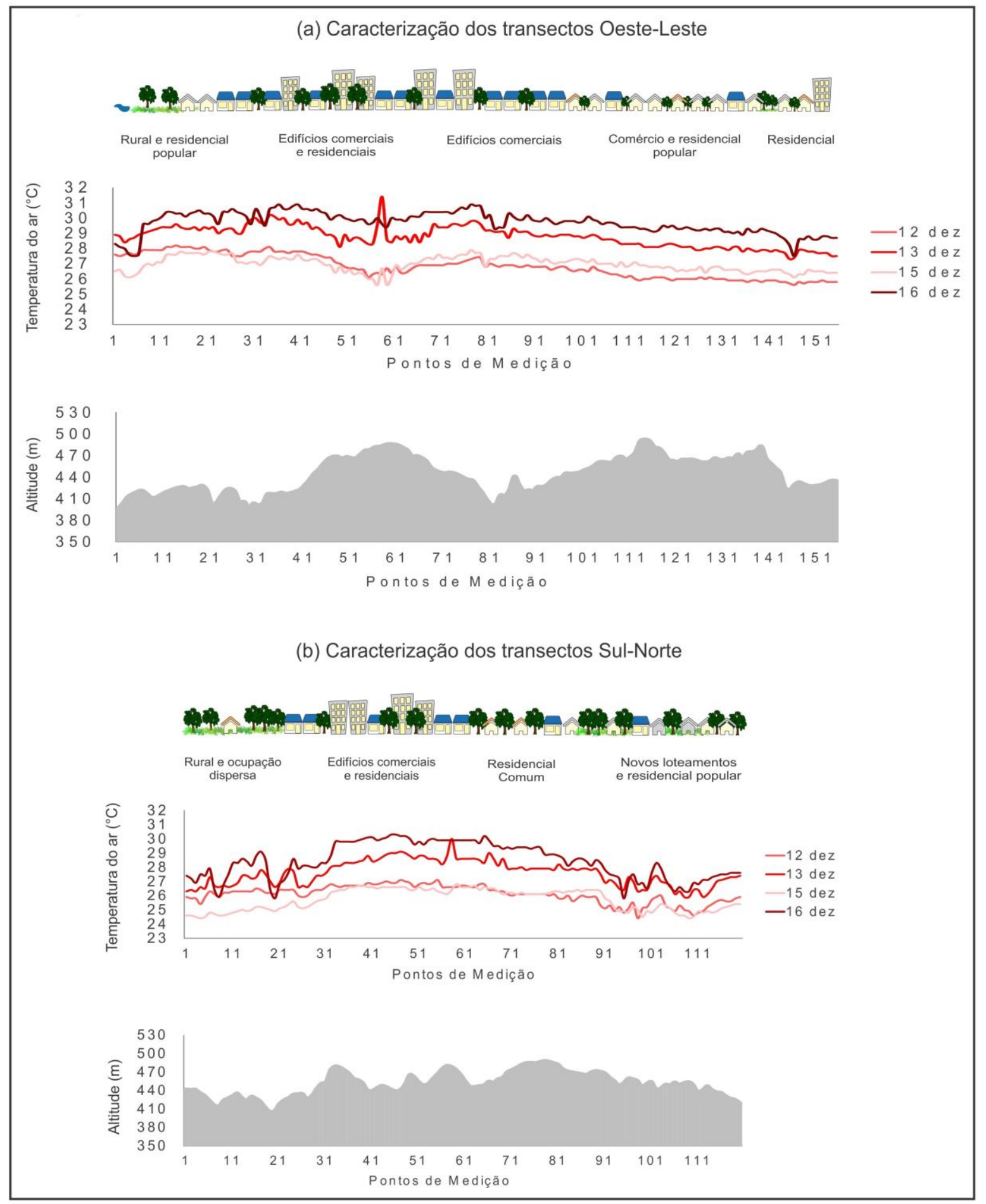

Figura 2 - Perfis térmicos e topográficos ilustrados de Presidente Prudente, dezembro de 2013: (a) transecto oeste-leste; e (b) transecto sul-norte. Fonte: Elaborado pela autora

Por sua vez, os locais com temperaturas mais reduzidas, entre $24,4^{\circ} \mathrm{C}$ e $25,4^{\circ} \mathrm{C}$, foram aqueles situados no início e no final do transecto sul-norte (Fig. 2). Tanto na direção sul, com predomínio de áreas rurais e ocupação dispersa, quanto nos bairros com residências populares a norte, o entorno é caracterizado por áreas verdes não edificadas e cobertura vegetal rasteira e arbórea, o que contribuiu para a diminuição das temperaturas. 


\section{VARIAÇÕES ESPACIAIS DAS TEMPERATURAS NOTURNAS EM PRESIDENTE PRUDENTE-SP EM EPISÓDIOS DE VERÃO}

Ainda sob influência da $\mathrm{mEc}$, ventos de $2,4 \mathrm{~m} / \mathrm{s}$, direção predominantemente de sudeste e pressão atmosférica de $957,7 \mathrm{hPa}$, os transectos móveis no dia 13 foram os que registraram a temperatura do ar mais elevada entre os demais dias. A máxima de $31,4^{\circ} \mathrm{C}$ foi registrada na área central, que apesar de ser arborizada, apresentou grande tráfego de veículos, e o fluxo de calor gerado no momento das medições resultou na temperatura do ar elevada.

A área representativa do rural no início do percurso oeste-leste, onde há uma pequena represa e a vegetação do entorno é constituída majoritariamente por coqueiros esparsos, também apresentou temperatura do ar mais elevada em relação aos outros dias (Fig. 2). Devido às condições atmosféricas, com dia ensolarado e calmaria, o corpo d'água ali presente absorveu mais radiação e, no período noturno, como demora a se resfriar em relação à superfície de entorno, foi registrado $28,9^{\circ} \mathrm{C}$. Seguindo este percurso, foram registradas temperaturas de $28,4^{\circ} \mathrm{C}$ nas primeiras quadras pouco construídas e com vegetação rasteira, a $29,6^{\circ} \mathrm{C}$ próximo aos bairros densamente edificados e com cobertura do telhado predominantemente de fibrocimento. Ao longo das áreas densamente construídas, com predomínio de edifícios residenciais e comerciais, registraram-se temperaturas entre $29,9^{\circ} \mathrm{C}$ e $30,2^{\circ} \mathrm{C}$. Já as temperaturas elevadas na área central com arborização (entre os pontos 51 e 61 do transecto oeste-leste e pontos 56 e 59 do sulnorte - Fig. 2) podem ser associadas às paradas nos semáforos, onde o calor produzido pelos automóveis repercutiu no aumento dos valores registrados. Temperaturas reduzidas foram registradas no fundo de vale vegetado próximo ao final do percurso oeste-leste $\left(27,3^{\circ} \mathrm{C}\right)$, a sul e a norte da cidade, onde se verificou valores entre $26,3^{\circ} \mathrm{C}$ e $25,9^{\circ} \mathrm{C}$, respectivamente.

A condição do tempo no dia 15, domingo, próximo ao horário de realização dos transectos móveis (21h), foi caracterizada por situação atmosférica estável, com velocidade do vento de 1,1 m/s. Entretanto, devido à ocorrência de precipitação $(57 \mathrm{~mm})$ com a chegada de um sistema frontal no dia 14 , observou-se que as diferenças térmicas diminuíram $\left(3,5^{\circ} \mathrm{C}\right)$. A temperatura máxima registrada foi $27,9^{\circ} \mathrm{C}$ nas proximidades do ponto 81 do transecto oesteleste (área com alta densidade construtiva e edifícios comerciais), enquanto a mínima de $24,4^{\circ} \mathrm{C}$ foi registrada no início do transecto sulnorte.

Logo no início do percurso oeste-leste, registrou-se $26,5^{\circ} \mathrm{C}$ de temperatura do ar. À medida que se avançou em direção às primeiras quadras pouco construídas, a temperatura diminuiu para $26,1^{\circ} \mathrm{C}$ e, em seguida, aumentou para $27^{\circ} \mathrm{C}$ e $27,8^{\circ} \mathrm{C}$ nas proximidades com bairros residenciais populares densamente construídos. Com relação à variação da temperatura entre os pontos 61 e 81 desse trajeto (Fig. 2), área densamente construída com predomínio de edifícios comerciais, houve o mesmo padrão de aumento nos valores verificado nos dias anteriores, chegando a apresentar $27,9^{\circ} \mathrm{C}$.

Por sua vez, o trecho do percurso sulnorte com alguns edifícios residenciais e a maior presença de comércios em direção ao centro da cidade apresentou variação entre $26,2^{\circ} \mathrm{C}$ e $26,7^{\circ} \mathrm{C}$. A partir do centro até o final da área residencial comum, com vegetação arbórea esparsa, as temperaturas variaram entre $26,4^{\circ} \mathrm{C}$ e $26,6^{\circ} \mathrm{C}$, diminuindo significativamente ao final do trajeto, caracterizado por menor densidade de construções e presença de áreas verdes nas proximidades dos bairros residenciais populares.

No que se refere às condições atmosféricas em Presidente Prudente no início dos transectos móveis no dia 16, segunda-feira, a pressão atmosférica foi de 956,7 hPa e não houve velocidade do vento significativamente mensurável. A diferença térmica nesse dia aumentou para $5,1^{\circ} \mathrm{C}$, com o registro da máxima de $30,9^{\circ} \mathrm{C}$ e mínima de $25,8^{\circ} \mathrm{C}$, sob a atuação da massa Tropical Continental (mTc).

A menor temperatura foi verificada no fundo de vale com vegetação arbórea no início do percurso sul-norte, enquanto a temperatura máxima foi registrada nas proximidades do ponto 


\section{VARIAÇÕES ESPACIAIS DAS TEMPERATURAS NOTURNAS EM PRESIDENTE PRUDENTE-SP EM EPISÓDIOS DE VERÃO}

41 do trajeto oeste-leste (Fig. 2), área densamente edificada e grande tráfego de veículos, cujo calor antropogênico gerado pode ter influenciado no registro de temperaturas acima de $30^{\circ} \mathrm{C}$ a partir desse ponto, em direção ao centro.

Nas áreas localizadas a oeste do centro, as temperaturas continuaram elevadas, entre $29,9^{\circ} \mathrm{C}$ e $30,9^{\circ} \mathrm{C}$, com o predomínio de valores acima de $30^{\circ} \mathrm{C}$. Ao adentrar a porção leste da cidade, registrou-se temperatura do ar de $29,4^{\circ} \mathrm{C}$, a qual diminuiu para $27,5^{\circ} \mathrm{C}$ ao passar com o veículo no fundo de vale vegetado próximo ao final do transecto oeste-leste.

Quanto às temperaturas verificadas ao longo do percurso sul-norte em direção à área central, registraram-se valores entre $28,8^{\circ} \mathrm{C}$ e $30,1^{\circ} \mathrm{C}$, com o predomínio de temperaturas entre $30^{\circ} \mathrm{C}$ e $29,3^{\circ} \mathrm{C}$ a partir do centro e em direção aos bairros residenciais com arborização nas calçadas.

No sentido dos bairros periféricos a norte, houve diminuição da temperatura de $29,4^{\circ} \mathrm{C}$ para $28,1^{\circ} \mathrm{C}$, e ao final desse transecto a temperatura variou de $27,4^{\circ} \mathrm{C}$ a $27,6^{\circ} \mathrm{C}$. Esta área é caracterizada por alguns lotes não edificados, com cobertura vegetal rasteira e árvores esparsas, além da proximidade com o rural e com a vegetação arbórea densa, que contribuíram para a diminuição da temperatura do ar.

\subsection{CONFIGURAÇÃO ESPACIAL E INTENSIDADE DAS ILHAS DE CALOR}

A forma e a intensidade das ilhas de calor podem variar no tempo e no espaço como resultado das características meteorológicas, da localização do sítio e dos equipamentos urbanos. O perfil clássico da temperatura do ar apresentado por Oke (1987), partindo do entorno rural em direção à área central da cidade, pode ser descrito como um pico na área mais urbanizada e um gradiente decrescente em direção ao limite entre o urbano e o rural.

Todavia, esse desenho das ilhas de calor é característico do ambiente temperado, ou dos grandes centros urbanos, os quais apresentam bairros mais extensos e homogêneos se comparados à complexidade paisagística das cidades menores. Nestas ocorre a interpenetração dos diferentes padrões construtivos em extensões territoriais reduzidas, fato que não propicia a formação de um padrão espacial pré-definido das ilhas de calor, onde o centro habitualmente apresenta as maiores temperaturas (AMORIM, 2017).

Em Presidente Prudente, verificou-se que no dia 12 de dezembro houve um padrão de temperaturas mais elevadas (acima de $27,5^{\circ} \mathrm{C}$ ) situado na porção oeste da cidade, mais especificamente ao longo dos bairros residenciais populares densamente construídos com pouca vegetação, e uma extensão desse aquecimento no sentido do centro (Fig. 3a). Já nos pontos localizados em bairros mais afastados da malha urbana, as características do entorno com cobertura vegetal proporcionaram temperaturas reduzidas, entre $24^{\circ} \mathrm{C}$ e $25^{\circ} \mathrm{C}$.

No dia 13 (Fig. 3b), a condição sinótica estável, associada a maior geração de calor antropogênico (aumento do fluxo de tráfego), propiciaram a configuração de um aquecimento mais acentuado no centro-oeste da cidade, e uma maior extensão da área com temperaturas elevadas, entre $29^{\circ} \mathrm{C}$ e $31,4^{\circ} \mathrm{C}$, em direção ao centro. No extremo sul foi possível identificar valores reduzidos $\left(26,3^{\circ} \mathrm{C}\right)$, enquanto a norte, com presença de vegetação arbórea densa em alguns locais, houve registros de temperaturas de $25,9^{\circ} \mathrm{C}$.

A diferença térmica no dia 15 foi inferior às registradas nos demais transectos, devido à homogeneização da intensidade das temperaturas após o episódio de instabilidade atmosférica e ocorrência de precipitação no dia $14 / 12$. No entanto, as diferenças verificadas foram nítidas e evidenciadas na disposição dos pontos mais aquecidos na área centro-oeste da cidade, com o predomínio de temperaturas acima de $27,5^{\circ} \mathrm{C}$. Por outro lado, os extremos sul e norte com construções esparsas e entorno rural permeável e vegetado, apresentaram diminuição das temperaturas, com registros entre $24,4^{\circ} \mathrm{C}$ e $25,5^{\circ} \mathrm{C}$ (Fig. 3c). 


\section{VARIAÇÕES ESPACIAIS DAS TEMPERATURAS NOTURNAS EM PRESIDENTE PRUDENTE-SP EM EPISÓDIOS DE VERÃO}

O dia 16 de dezembro apresentou uma configuração espacial dos valores de temperatura do ar semelhante à identificada no dia 13. A porção centro-oeste da malha urbana continuou mais aquecida do que os extremos sul e norte, com uma extensão dos valores elevados (acima de $29^{\circ} \mathrm{C}$ ) também em direção à zona leste (Fig. 3d). Além disso, foram verificados pontos com temperatura mais elevada no sentido norte $\left(28,3^{\circ} \mathrm{C}\right)$, próximo aos conjuntos habitacionais populares e novos loteamentos, e no início do percurso sul-norte $\left(29,1^{\circ} \mathrm{C}\right)$, onde houve um fluxo maior de veículos durante o monitoramento.

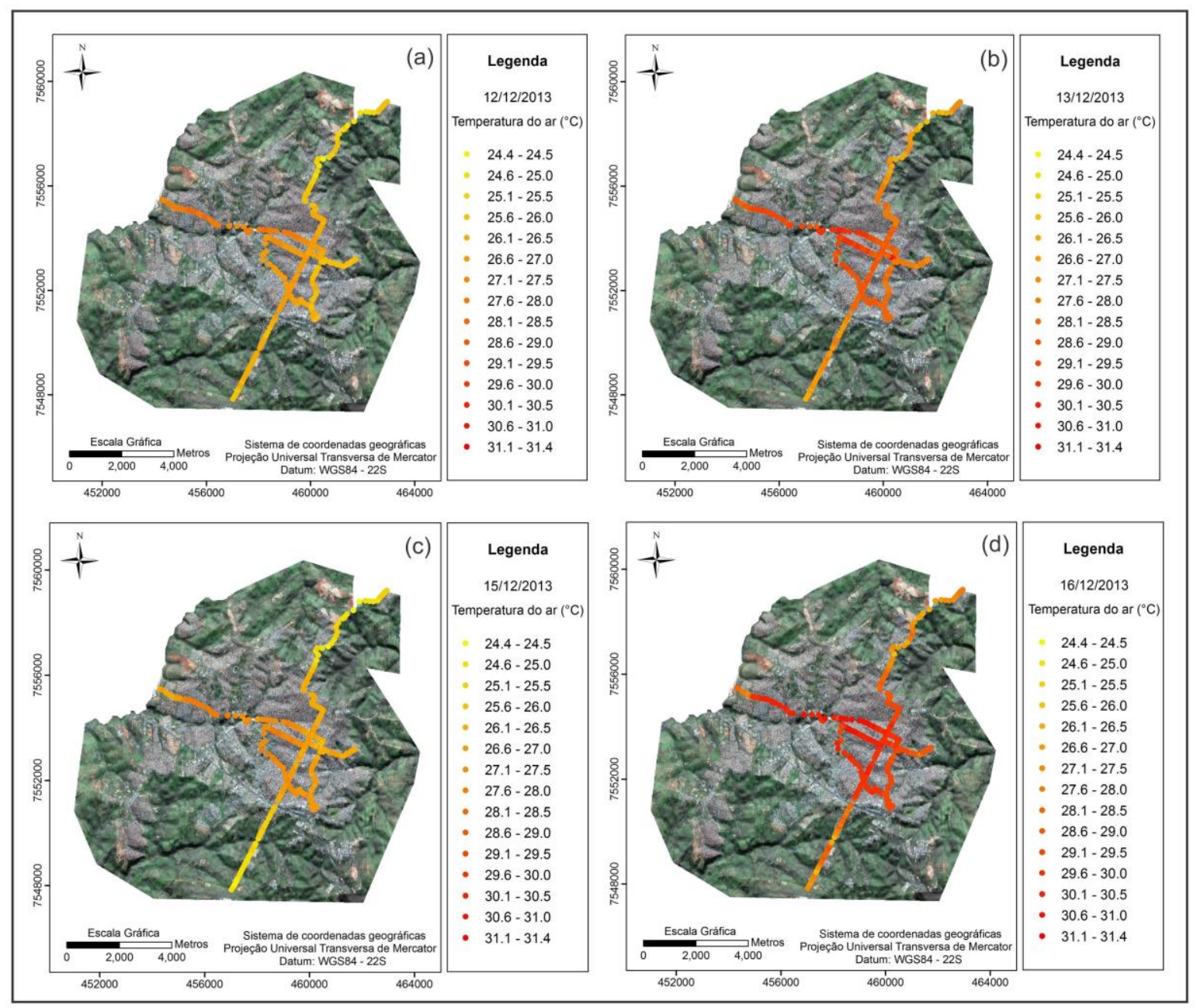

Figura 3 - Transectos térmicos noturnos em Presidente Prudente, dezembro de 2013: (a) 12/12/2013; (b) 13/12/2013; (c) 15/12/2013; e (d) 16/12/2013.Fonte: Elaborado pela autora.

De maneira geral, apesar de haver deslocamentos do núcleo mais aquecido durante os dias de medições, a área da cidade que mais se destacou com altos valores de temperatura foi a porção oeste. As temperaturas do ar elevadas foram provavelmente uma combinação da escassa cobertura vegetal com a alta densidade de construções. Com relação à intensidade das ilhas de calor, os valores registrados são considerados significativos para uma cidade de porte médio como Presidente Prudente, tendo em vista que após a passagem de um sistema frontal com a ocorrência de precipitação, a diferença térmica registrada no dia seguinte atingiu $3,5^{\circ} \mathrm{C}$ (Tabela 1 ). 


\section{VARIAÇÕES ESPACIAIS DAS TEMPERATURAS NOTURNAS EM PRESIDENTE PRUDENTE-SP EM EPISÓDIOS DE VERÃO}

Tabela 1 - Temperatura do ar, velocidade e direção do vento, e sistemas atmosféricos atuantes durante os transectos em Presidente Prudente, dezembro de 2013, às 21h00min

\begin{tabular}{|c|c|c|c|c|c|c|}
\hline \multirow{2}{*}{ Data } & \multicolumn{3}{|c|}{ Temperatura do ar $\left({ }^{\circ} \mathrm{C}\right)$} & \multicolumn{2}{|c|}{ Vento $(\mathrm{m} / \mathrm{s})$} & \multirow{2}{*}{$\begin{array}{c}\text { Sistema } \\
\text { Atmosférico }\end{array}$} \\
\hline & Máx. & Mín. & $\Delta T$ & Vel. & Dir. & \\
\hline $12 / 12 / 2013$ & 28,2 & 24,4 & 3,8 & 2,5 & SE & $\mathrm{mEc}$ \\
\hline $13 / 12 / 2013$ & 31,4 & 25,9 & 5,5 & 2,4 & SE & $\mathrm{mEc}$ \\
\hline $15 / 12 / 2013$ & 27,9 & 24,4 & 3,5 & 1,1 & $E$ & $\mathrm{mTc}$ \\
\hline $16 / 12 / 2013$ & 30,9 & 25,8 & 5,1 & - & - & $\mathrm{mTc}$ \\
\hline
\end{tabular}

Fonte: Elaborado pela autora

Além disso, destaca-se que as maiores diferenças excederam $5^{\circ} \mathrm{C}$ nos dias com atmosfera estável, vento fraco e incidência solar no período vespertino. Tais condições evidenciaram a configuração de um padrão de aquecimento mais definido sobre a área centrooeste da cidade, caracterizada por alta densidade construtiva e elevado fluxo de calor gerado pelas atividades humanas. Em contrapartida, a presença de cobertura vegetal não apenas no entorno rural, mas também em áreas construídas, proporcionou temperaturas mais baixas durante os dias de medições.

\section{CONSIDERAÇÕES FINAIS}

A configuração espacial da ilha de calor apresentada nos estudos clássicos da climatologia urbana em ambiente temperado, ou em áreas metropolitanas localizadas em diferentes tipos climáticos-com valores elevados no centro, diminuindo em direção a periferia, nem sempre é verificada nas cidades de menor porte no ambiente tropical. Em Presidente Prudente foi identificada uma notável extensão do núcleo aquecido para a porção oeste da cidade, sendo que a causa para essa variação espacial pode ser atribuída a dois aspectos principais: morfologia urbana (bairros densamente construídos) e cobertura da superfície (majoritariamente impermeável e, consequentemente, com pouca vegetação).

Portanto, estas foram as características mais importantes na diferenciação entre as áreas mais aquecidas $\mathrm{e}$ as áreas com temperaturas reduzidas em Presidente Prudente, com diferentes intensidades associadas às condições meteorológicas de cada dia de registro. Sob situações ideais de estabilidade atmosférica, ou seja, com céu claro e com vento calmo, ocorreu a máxima intensidade da ilha de calor. Além disso, a diminuição das atividades antropogênicas resultou em efeito positivo, visto que as temperaturas do ar noturnas diminuíram no final de semana com a redução no fluxo de tráfego.

Como as cidades tropicais apresentam, naturalmente, temperaturas elevadas na maior parte do ano, a formação de ilhas de calor intensifica o desconforto térmico da população, sobretudo daquelas que habitam bairros populares com baixo padrão construtivo. Tendo em vista a influência das atividades, fluxos e materiais constituintes do ambiente urbano na configuração do seu campo térmico, ressalta-se a importância das áreas vegetadas na diminuição das temperaturas do ar, principalmente durante o verão.

A vegetação proporciona a diminuição da temperatura do ar por meio da evapotranspiração, ou seja, na passagem da água do estado líquido para o estado de vapor, o calor sensível é transformado em latente (AMORIM, 2017). A cobertura vegetal arbórea também promove o sombreamento e protege as superfícies da incidência direta dos raios solares, minimizando o armazenamento de calor pelos materiais urbanos durante o dia. 


\section{VARIAÇÕES ESPACIAIS DAS TEMPERATURAS NOTURNAS EM PRESIDENTE PRUDENTE-SP EM EPISÓDIOS DE VERÃO}

\begin{abstract}
Nesse sentido, destaca-se a necessidade de se incorporar as características climáticas locais no planejamento urbano, bem como priorizar a utilização de materiais construtivos adequados, e realizar um projeto de arborização em conjunto com a população visando a melhoria da qualidade de vida no ambiente urbano.
\end{abstract}

\section{REFERÊNCIAS}

AMORIM, M. C. C. T. O clima urbano de Presidente Prudente/SP. 2000. 378p. Tese (Doutorado em Geografia) - Faculdade de Filosofia, Letras e Ciências Humanas, Universidade de São Paulo, São Paulo.

AMORIM, M. C. C. T. Intensidade e forma da ilha de calor urbana em Presidente Prudente/SP. Geosul, v. 20, n. 39: 65-82, UFSC Florianópolis/Brasil, 2005.

AMORIM, M. C. C. T. Teoria e método para o estudo das ilhas de calor em cidades tropicais de pequeno e médio porte. 2017. Tese (Livre Docência) - Faculdade de Ciências e Tecnologia, Universidade Estadual Paulista, Presidente Prudente.

AMORIM, M. C. C. T.; DUBREUIL, V.; QUENOL, H.; SANT'ANNA NETO, J. L. Características das ilhas de calor em cidades de porte médio: exemplos de Presidente Prudente (Brasil) e Rennes (França). Confins (Paris), v. 7, p. 1-16, 2009.

AMORIM, M. C. C. T.; MONTEIRO, A. As temperaturas intraurbanas: exemplos do Brasil e de Portugal. Confins (Paris), v. 13, p. 1-18, 2011.

AMORIM, M. C. C. T.; DUBREUIL, V.; CARDOSO, R. S. MODELAGEM ESPACIAL DA ILHA DE CALOR URBANA EM PRESIDENTE PRUDENTE (SP), BRASIL. Revista Brasileira de Climatologia, v. 16, p. 29-45, 2015.

BARBOSA, H. P.; AMORIM, M. C. C. T. Clima urbano em Presidente Prudente/SP: diferenças térmicas e higrométricas urbano/rural em episódios de outono. Revista GeoNorte, v. 2, p. 220-232, 2012.

CARDOSO, R. S.; AMORIM, M. C. C. T. Análise do clima urbano a partir da segregação socioespacial e socioambiental em Presidente Prudente-SP, Brasil. GEOSABERES: Revista de Estudos Geoeducacionais, v. 6, p. 122-136, 2015.
ELIASSON, I. Intra-urban noctural temperature differences: multivariate approach. Climate Research, 7: 21-30, 1996.

FIALHO, E. S. Ilha de calor em cidade de pequeno porte: Caso de Viçosa, na Zona da Mata Mineira. 2009. Tese (Doutorado em Geografia Física) Faculdade de Filosofia, Letras e Ciências Humanas, Universidade de São Paulo, São Paulo.

GARCÍA, F. F. Manual de climatologia aplicada: clima, medio ambiente y planificación. Madrid: Editorial síntesis, S.A., 1995. 285p.

HART, M.; SAILOR, D. J. Assessing causes in spatial variability in urban heat island magnitude. In: Proceedings of the Seventh Symposium on the Urban Environment (September, 2007). San Diego, California, USA. 2007, p.1-6.

INSTITUTO BRASILEIRO DE GEOGRAFIA E ESTATístICA. IBGE. População estimada 2016. Disponível em: <http://cod.ibge.gov.br/232SS>. Acesso em: 7 mar. 2017.

JAMEI, E.; OSSEN, D. R. Intra urban air temperature distributions in historic urban center. American Journal of Environmental Science, 8 (5), 503-509, 2012.

MONTEIRO, C. A. F. Teoria e Clima Urbano. São Paulo: USP, 1976.

MONTEIRO, C. A. F. Adentrar a cidade para tomar-lhe a temperatura. Geosul, Florianópolis: Edufsc, n. 9, ano V, p. 61-79, 1990.

MYRUP, L. O. A Numerical Model of the Urban Heat Island. Journal of Applied Meteorology, 8, 908-918. $1969 . \quad$ doi: http://dx.doi.org/10.1175/15200450(1969)008<0908:ANMOTU>2.0.CO;2.

OKE, T. R. The distinction between canopy and boundary-layer urban heat islands. Atmosphere, 14:4, 268-277, 1976.

OKE, T. R. Boundary Layer Climates. 2nd ed. London: Methuen \& Co., 1987, 435 p.

OKE, T. R. Initial Guidance to Obtain Representative Meteorological Observations at Urban Sites. IOM Report 81, WMO/TD. No. 1250.World Meteorological Organization, Geneva, 2006. Disponível em < http://www.wmo.int/pages/prog/www/IMOP/pu blications/IOM-81/-UrbanMetObs.pdf>. Acesso em: 12 ago. 2014.

ORTIZ PORANGABA, G. F. O clima urbano das cidades do interior do Estado de São Paulo: uma 


\section{VARIAÇÕES ESPACIAIS DAS TEMPERATURAS NOTURNAS EM PRESIDENTE PRUDENTE-SP EM EPISÓDIOS DE VERÃO}

análise do campo térmico de Assis, Cândido Mota, Maracaí e Tarumã. 2015. 354f. Tese (Doutorado em Geografia) - Faculdade de Ciências e Tecnologia, Universidade Estadual Paulista, Presidente Prudente.

PRESTON-WHYTE, R. A. A spatial model of an urban heat island. Journal of Applied Meteorology, 9, 571-573, 1970.

SAKAKIBARA, Y.; MATSUI, E. Relation between heat island intensity and city size indices/urban canopy characteristics in settlements of Nagano basin, Japan. Geographical Review of Japan, 78: 812-24, 2005.

STEWART, I. D. Redefining the urban heat island. 2011. 368p. Thesis (Doctor of Philosophy). The Faculty of Graduate Studies, The University of British Columbia, Vancouver.

UGEDA JUNIOR, J. C. Clima urbano e planejamento na cidade de Jales-SP. 2012. $383 f$. Tese (Doutorado em Geografia) - Faculdade de Ciências e Tecnologia, Universidade Estadual Paulista, Presidente Prudente.

VAN HOVE, L. W. A.; STEENEVELD, G. J; JACOBS, C. M. J.; HEUSINKVELD, B. G.; ELBERS, J. A.; MOORS, E. J; HOLTSLAG, A. A. M. Exploring the Urban Heat Island Intensity of Dutch cities; Assessment based on a literature review, recent meteorological observations and datasets provided by hobby meteorologists. Wageningen, Alterra, Alterra report 2170. 60 pp.; 11 fig.; 13 tab.; 120 ref. 2011 